\title{
Monte Carlo investigation of backscatter factors for skin dose determination in interventional neuroradiology procedures
}

\author{
Artur Omar ${ }^{\mathrm{a}}$, Hamza Benmakhlouf ${ }^{\mathrm{a}, \mathrm{b}}$, Maria Marteinsdottir ${ }^{\mathrm{a}}$, Robert Bujila ${ }^{\mathrm{a}}$, Patrik Nowik ${ }^{\mathrm{a}}$, \\ and Pedro Andreo ${ }^{\mathrm{b}}$ \\ ${ }^{a}$ Dept. of Medical Physics, Karolinska University Hospital, Stockholm, Sweden; ${ }^{b}$ Division of \\ Medical Radiation Physics, University of Stockholm and Karolinska Institute, Stockholm, Sweden
}

\begin{abstract}
Complex interventional and diagnostic x-ray angiographic (XA) procedures may yield patient skin doses exceeding the threshold for radiation induced skin injuries. Skin dose is conventionally determined by converting the incident air kerma free-in-air into entrance surface air kerma, a process that requires the use of backscatter factors. Subsequently, the entrance surface air kerma is converted into skin kerma using mass energy-absorption coefficient ratios tissue-to-air, which for the photon energies used in XA is identical to the skin dose. The purpose of this work was to investigate how the cranial bone affects backscatter factors for the dosimetry of interventional neuroradiology procedures.
\end{abstract}

The PENELOPE Monte Carlo system was used to calculate backscatter factors at the entrance surface of a spherical and a cubic water phantom that includes a cranial bone layer. The simulations were performed for different clinical $\mathrm{x}$-ray spectra, field sizes, and thicknesses of the bone layer.

The results show a reduction of up to $15 \%$ when a cranial bone layer is included in the simulations, compared with conventional backscatter factors calculated for a homogeneous water phantom. The reduction increases for thicker bone layers, softer incident beam qualities, and larger field sizes, indicating that, due to the increased photoelectric crosssection of cranial bone compared to water, the bone layer acts primarily as an absorber of low-energy photons.

For neurointerventional radiology procedures, backscatter factors calculated at the entrance surface of a water phantom containing a cranial bone layer increase the accuracy of the skin dose determination.

Keywords: Diagnostic x-ray dosimetry, backscatter factors, skin dose, interventional neuroradiology

\section{INTRODUCTION}

Since the advent of medical x-ray imaging, x-ray examinations have significantly contributed to improved clinical outcomes and increased population health. The radiation dose from x-ray examinations is, however, also one of the largest contributors to the exposure of the world's population. ${ }^{1}$ Some types of examinations, such as interventional procedures, can result in absorbed doses to tissues inducing deterministic and stochastic tissue reactions. ${ }^{2}$ Interventional procedures are a type of x-ray angiographic (XA) procedure where the vasculature of tissue and organs is imaged by fluoroscopy and digital subtraction angiography (DSA) techniques. Interventional procedures are either diagnostic - identification of a vascular condition, or therapeutic - treatment of a vascular condition. Typical conditions treated in neurointerventional radiology are aneurysms, strokes, arteriovenous malformations (AVM), and vascular tumors.

Complex interventional XA procedures are in general high dose examinations that may result in patient skin doses exceeding the threshold for radiation induced skin injuries. ${ }^{3}$ The approximate threshold single doses for radiation induced skin injuries are 2 Gy for early transient erythema, 3 Gy for temporary epilation, 6 Gy for main erythema reaction, $7 \mathrm{~Gy}$ for permanent epilation, and $10 \mathrm{~Gy}$ for dermal atrophy. ${ }^{2}$ In order to assess the risk of developing a skin injury from an XA procedure, and to evaluate the need for early treatments that may mitigate the skin reaction, it is important to determine the absorbed dose to the patient's skin as accurately as possible. ${ }^{4}$

The skin dose is usually determined converting first the incident air kerma free-in-air at a given distance from the x-ray source, $\left(K_{\text {air }}\right)_{\text {air }}$, into the entrance surface air kerma, $\left(K_{\text {air }}\right)_{\text {surf }}$, and in a second step transferring this quantity into the

Medical Imaging 2014: Physics of Medical Imaging, edited by Bruce R. Whiting, Christoph Hoeschen, Despina Kontos, Proc. of SPIE Vol. 9033, 90331T · C 2014 SPIE · CCC code: 1605-7422/14/\$18 · doi: 10.1117/12.2042159 
patient entrance surface tissue kerma, $\left(K_{\text {tissue }}\right)_{\text {surf }}$, which for kilovoltage x-rays coincides with the entrance surface tissue dose. The two-step conversion requires backscatter factors to obtain the entrance surface air kerma from the incident air kerma free-in-air, and mass energy-absorption coefficient ratios tissue-to-air to convert the entrance surface air kerma into tissue kerma, both factors being defined at the surface of the patient. Note that, in accordance with wellestablished formalisms for kilovoltage dosimetry, tissue can be substituted by water.

The ICRU Report- $74^{5}$ and IAEA TRS- $457^{6}$ provide values of backscatter factors for diagnostic kilovoltage spectra, ranging from 50 to $150 \mathrm{kV}$, for $2.5 \mathrm{~mm} \mathrm{Al}, 3 \mathrm{~mm} \mathrm{Al}$, and $3 \mathrm{~mm} \mathrm{Al}+0.1 \mathrm{~mm} \mathrm{Cu}$ filtration. The data provided in those reports are from Petoussi-Henss et al., ${ }^{7}$ calculated using the Monte Carlo method, for a water, PMMA, and ICRU tissue homogeneous phantoms. More recently, backscatter factors and mass energy-absorption coefficient ratios water to air have been calculated for a homogeneous water phantom, covering the whole range of diagnostic beam qualities used in interventional radiology ${ }^{8}$. The data in these publications are for a cubic $30 \mathrm{~cm}$ x $30 \mathrm{~cm}$ front surface and $15 \mathrm{~cm}$ thick phantom, which approximates the body of adult patients. The influence of phantom thickness on backscatter factors has been investigated by Benmakhlouf et al., ${ }^{9}$ providing correction factors ranging from $2-12 \%$ for a $5 \mathrm{~cm}$ thick homogeneous water phantom, and reaching a plateau of about $\pm 1 \%$ for thicknesses beyond $13 \mathrm{~cm}$. Although a large amount of data on backscatter factors is available, they are limited to cubic homogeneous phantoms with dimensions that approximate the body of adult ( $15 \mathrm{~cm}$ thickness) and pediatric $(<15 \mathrm{~cm}$ thickness $)$ patients.

The number of investigations on the effect of a superficial bone layer, e.g., cranial bone, on backscatter radiation for kilovoltage x-ray beams is limited. Ma et al. ${ }^{10}$ used the EGS4 Monte Carlo system to calculate ratios of backscatter factors, water to compact bone, for six kilovoltage $\mathrm{x}$-ray spectra in the range 50-300 $\mathrm{kV}(0.875-20.8 \mathrm{~mm} \mathrm{Al} \mathrm{HVL})$. They concluded that backscatter factors for bone differ from those for water by up to $20 \%$ for a $100 \mathrm{kV}$ beam (HVL of 2.65 $\mathrm{mm} \mathrm{Al}$ ) with a $10 \mathrm{~cm} \times 10 \mathrm{~cm}$ field size. However, these results do not provide an accurate representation of the effect of a bone layer, as the calculations account for the bulk replacement of a large water phantom by a bone phantom. Butson et al. ${ }^{11}$ used an Attix parallel plate ionization chamber to measure the difference in absorbed dose to water for $\mathrm{x}$ rays backscattered from a $10 \mathrm{~mm}$ thick bone layer. This was done for typical beam qualities used in superficial x-ray radiotherapy: $50 \mathrm{kV}$ (HVL of $1.4 \mathrm{~mm} \mathrm{Al}$ ), $100 \mathrm{kV}$ (HVL of $3.72 \mathrm{~mm} \mathrm{Al}$ ), and $150 \mathrm{kV}$ (HVL of $0.627 \mathrm{~mm} \mathrm{Cu}$ ). They reported a reduction by up to $12.5 \%$ in absorbed dose to water at the surface of a $30 \mathrm{~cm}$ x $30 \mathrm{~cm}$ x $30 \mathrm{~cm}$ solid water phantom.

The purpose of this work is twofold. First, to establish a methodology that is appropriate for the calculation of backscatter factors suitable for skin dose determinations for neurointerventional radiology procedures, including the use of a suitable phantom approximating the head of an adult patient. Second, to apply the established methodology to investigate the effect of a shallow cranial bone layer on backscatter factors.

\section{METHODS AND MATERIALS}

\subsection{Monte Carlo calculation of backscatter factors}

The user-code PenEasy, ${ }^{12}$ based on the PENELOPE Monte Carlo system, ${ }^{13}$ was used to score the photon fluence differential in energy, $\Phi_{E}$, at the entrance surface of a water phantom containing a shallow layer of cranial bone. The backscatter factor for the x-ray spectrum $S$ can then be calculated as

$$
B_{\mathrm{air}}(S)=\frac{\left(K_{\mathrm{air}, S}\right)_{\mathrm{surf}}^{\mathrm{p}+\mathrm{s}}}{\left(K_{\mathrm{air}, S}\right)_{\mathrm{air}}^{\mathrm{p}}}=\frac{\int_{0}^{\mathrm{E}_{\mathrm{max}}} E\left[\Phi_{E}\right]_{\text {surf }}^{\mathrm{p}+\mathrm{s}}\left[\mu_{\mathrm{en}}(E) / \rho\right]_{\mathrm{air}} \mathrm{d} E}{\int_{0}^{\mathrm{E}_{\max }} E\left[\Phi_{E}\right]_{\mathrm{air}}^{\mathrm{p}}\left[\mu_{\mathrm{en}}(E) / \rho\right]_{\mathrm{air}} \mathrm{d} E},
$$

where $\left(K_{\mathrm{air}, S}\right)_{\text {surf }}^{\mathrm{p}+\mathrm{s}}$ and $\left[\Phi_{E}\right]_{\text {surf }}^{\mathrm{p}+\mathrm{s}}$ are, respectively, the air kerma and photon fluence at the phantom surface for the incident primary $(\mathrm{p})$ plus back-scattered photons $(\mathrm{s}),\left(K_{\mathrm{air}, S}\right)_{\text {air }}^{\mathrm{p}}$ and $\left[\Phi_{E}\right]_{\text {air }}^{\mathrm{p}}$ are the air kerma-free-in-air and incident primary photon fluence, respectively, and $\left[\mu_{\mathrm{en}}(E) / \rho\right]_{\text {air }}$ is the photon mass energy-absorption coefficient, taken from the web-based NIST database, ${ }^{14}$ for photon energy $E$. 
Due to their short range, electrons generated by photon interactions for diagnostic x-ray energies (below $150 \mathrm{keV}$ ) practically deposit their energy locally, and they have a negligible radiation yield (bremsstrahlung production) in bone and water. Therefore the electron transport was switched off taking their cut-off energy equal to the maximum incident photon energy. The photon transport was simulated down to a cut-off energy of $1 \mathrm{keV}$, at which point the photons were absorbed in the medium. A minimum of five billion photon histories were initiated in each simulation, with the photon source placed at $60 \mathrm{~cm}$ from the phantom surface, approximating the focus-to-surface distance (FSD) in interventional procedures. It should be noted that the dependence of backscatter factors on the FSD is considered to be negligible for diagnostic $\mathrm{x}$-ray spectra ${ }^{5}$. The backscattered photon spectra were scored in a voxel with a volume equivalent to $1 \mathrm{~cm} \times 1 \mathrm{~cm} \times 0.01 \mathrm{~cm}$, positioned at the centre of the entrance surface of the phantom. The scoring voxel was shaped to conform to the surface of the phantom.

\subsection{Phantom geometry}

In order to calculate backscatter factors using equation (1), a phantom geometry approximating the head of an adult patient was established. The head, for dosimetric purposes, consists of the scalp (skin, $\rho=1.09 \mathrm{~g} \mathrm{~cm}^{-3}$ and muscle $\rho=1.05 \mathrm{~g} \mathrm{~cm}^{-3}$; approximated as water), brain $\left(\rho=1.04 \mathrm{~g} \mathrm{~cm}^{-3}\right.$; approximated as water), and cranial bone (ICRU skeleton-cranium, ${ }^{15} \rho=1.61 \mathrm{~g} \mathrm{~cm}^{-3}$ ). The cranial bone is comprised of diploe tissue (ICRU skeleton-spongiosa, ${ }^{15}$ $\rho=1.18 \mathrm{~g} \mathrm{~cm}^{-3}$ ) sandwiched between compact bone (ICRU skeleton-cortical bone, ${ }^{15} \rho=1.92 \mathrm{~g} \mathrm{~cm}^{-3}$ ). The thickness of the cranial bone varies from individual to individual and with location on the cranium, ranging from about $2.5 \mathrm{~mm}$ to $12.5 \mathrm{~mm}$ with an average thickness of $6 \mathrm{~mm} .^{16-17}$ The thickness of the scalp varies with age and sex of the individual, ranging in mean thickness from about $4.5 \mathrm{~mm}$ to $5.5 \mathrm{~mm} .{ }^{18}$

There is no general consensus on the size of a standardized head phantom for radiation dosimetry. In stereotactic radiosurgery, the standardized head phantom is a $16 \mathrm{~cm}$ diameter water equivalent sphere. The geometry was proposed by AAPM TG- $42^{19}$ to consolidate inter-institutional reference dosimetry and dose verification of radiation therapy Gamma Knife units. The proposed phantom size was based on various differently sized stylized and anthropomorphic phantoms used for dose verification, with consideration taken to accommodate field sizes used by linacs as well as Gamma Knife units. For diagnostic radiology, the standardized head phantom for determination of computed tomography dose index (CTDI) is a $16 \mathrm{~cm}$ diameter PMMA cylinder $\left(\rho=1.19 \mathrm{~g} \mathrm{~cm}^{-3}\right)$, which approximately corresponds to a $19 \mathrm{~cm}$ diameter water equivalent cylinder. Huda et al. ${ }^{20}$ investigated head size dimensions from head CT images of 127 patients, concluding that an average adult head has a dimension of $18.6 \pm 0.8 \mathrm{~cm}$ posterior-anterior and of $14.7 \pm 0.8$ $\mathrm{cm}$ lateral, or for dosimetry purposes, a water equivalent diameter of about $18 \mathrm{~cm}$.

In order to establish a phantom geometry suitable for calculation of backscatter factors for neurointerventional radiology procedures, different phantom configurations were investigated:

I. Spherical $18 \mathrm{~cm}$ diameter; $\left(B_{\text {air }}\right)_{\text {sphere,18 }}$

(a) Homogeneous water phantom

(b) Water phantom with a superficial cranial bone layer

(c) Water phantom with a cranial bone layer beneath the superficial scalp ( $5 \mathrm{~mm}$ water $)$; $\left(B_{\text {air }}\right)_{\text {sphere,18 }}^{\text {scalp }}$

II. Cubic $18 \mathrm{~cm} \times 18 \mathrm{~cm} \times 18 \mathrm{~cm}$ and spherical $16 \mathrm{~cm}$ diameter; $\left(B_{\text {air }}\right)_{\text {cube,18 }}$ and $\left(B_{\text {air }}\right)_{\text {sphere,16 }}$

(a) Homogeneous water phantom

(b) Water phantom with a superficial cranial bone layer

The investigation was done for two differently sized spherical phantoms and a cubic phantom (I. and II.) to analyze the dependence of backscatter factors on the size and shape of the phantom. Furthermore, the sensitivity of backscatter factors to the configuration, i.e., the complexity, of the head phantom model was investigated, I. (b-c).

Backscatter factors were calculated for the clinical x-ray spectra shown in Table 1, generated with the software SpekCalc, ${ }^{21}$ for field sizes of $5 \mathrm{~cm} \times 5 \mathrm{~cm}, 10 \mathrm{~cm} \times 10 \mathrm{~cm}$, and $15 \mathrm{~cm} \mathrm{x} 15 \mathrm{~cm}$, and bone layers of thicknesses between $2.5 \mathrm{~mm}-12.5 \mathrm{~mm}$. The selected incident beam qualities and field sizes cover the range of clinically used settings for neurointerventional radiology procedures. Closer analysis of the effect of a superficial cranial bone layer on the backscatter factors was done by simulation of monoenergetic photon beams for a $6 \mathrm{~mm}$ thick cranial bone layer. 
Table 1. Clinical beam qualities, specified in terms of kilovoltage $(\mathrm{kV})$, filtration, first half-value layer $\left(\mathrm{HVL}_{1}\right)$, homogeneity coefficient $\left(h=\mathrm{HVL}_{1} / \mathrm{HVL}_{2}\right)$, and mean photon energy, corresponding to a typical range of qualities used for neurointerventional procedures.

\begin{tabular}{c|cccccc}
\hline Beam Quality & $\mathrm{kV}$ & $\begin{array}{c}\text { Filtration } \\
(\mathrm{mm} \mathrm{Al})\end{array}$ & $\begin{array}{c}\text { Filtration } \\
(\mathrm{mm} \mathrm{Cu})\end{array}$ & $\mathrm{HVL}_{1}$ & $h$ & $\begin{array}{c}\text { Mean energy } \\
(\mathrm{keV})\end{array}$ \\
\hline $\mathrm{Q}_{1}$ & 120 & $2.5+1.0$ & 0.9 & 11.2 & 0.95 & 75.2 \\
$\mathrm{Q}_{2}$ & 90 & $2.5+1.0$ & 0.2 & 6.4 & 0.84 & 55.5 \\
$\mathrm{Q}_{3}$ & 60 & 2.5 & 0.0 & 2.0 & 0.71 & 36.0 \\
\hline
\end{tabular}

\section{RESULTS AND DISCUSSION}

Table 2 shows ratios of backscatter factors calculated for spherical and cubic phantoms of different sizes. Results are shown for various cranial bone layer thicknesses and field sizes, for the three beam qualities of Table 1 . The results show that, compared to the $18 \mathrm{~cm} \times 18 \mathrm{~cm} \times 18 \mathrm{~cm}$ cubic phantom, the amount of backscattered photons at the entrance surface of the $18 \mathrm{~cm}$ diameter spherical phantom decreases for increasing field sizes. This is due to the $\mathrm{x}$-ray beam covering a smaller amount of phantom material in the spherical phantom than in the cubic phantom. For softer incident beam qualities and thicker bone layers the attenuation of photons increases and therefore the difference in irradiated volume becomes less important. For the $5 \mathrm{~cm} \times 5 \mathrm{~cm}$ field size the difference in irradiated volume is negligible and the backscatter from the spherical phantom is slightly greater than from the cubic phantom. The difference in backscatter factors for a spherical phantom compared to a cubic phantom are generally within $1 \%$, with a maximum difference of $5.2 \%$ and $2.6 \%$ for a homogeneous water phantom and a water phantom containing a superficial $5 \mathrm{~mm}$ bone layer, respectively. The dependence of backscatter factors on the size of the spherical phantom was also investigated. The backscatter from the spherical $18 \mathrm{~cm}$ diameter phantom is shown to be larger than from the $16 \mathrm{~cm}$ diameter phantom, with increasing difference for larger field sizes. This is expected due to the larger irradiated volume of the $18 \mathrm{~cm}$ diameter sphere. The difference in backscatter factors for an $18 \mathrm{~cm}$ diameter spherical phantom compared to a $16 \mathrm{~cm}$ diameter spherical phantom are within $1 \%$ generally. The maximum difference is $1.6 \%$ and $1.1 \%$ for a homogeneous water phantom and a water phantom containing a superficial $5 \mathrm{~mm}$ bone layer, respectively.

The sensitivity of backscatter factors to the complexity of the head phantom model was investigated for the different configurations of the $18 \mathrm{~cm}$ diameter spherical water phantom. Figure 1 shows backscatter factors as a function of the cranial bone layer thickness, calculated for different thicknesses and field sizes for the three beam qualities of Table 1. Results have been normalized to backscatter factors for a homogeneous water phantom (zero bone layer thickness). The results show that the inclusion of a superficial water layer (approximating the scalp), by placing the bone at $5 \mathrm{~mm}$ depth in the spherical water phantom, results in an increased amount of backscattered photons for "soft" incident beam qualities. This is due to the increased back scattering of primary photons from the scalp toward the phantom entrance surface. For thick bone layers, these backscattered photons (from the scalp) contribute considerably to the total backscatter due to the attenuation in bone of backscattered photons generated at the distal end of the bone layer, an effect that increases with its thickness. Therefore, the inclusion of a superficial water layer approximating the scalp has a larger effect for thicker bone layers. For "hard" beam qualities and narrow bone layers the influence of the scalp is much smaller, becoming almost negligible compared with phantom backscattering and therefore backscatter factors decrease. Generally, the difference in the calculated backscatter factors is of the order of $1-2 \%$, with a maximum difference of about $4 \%$. It is also interesting to note that, due to the scalp effect, backscatter factors do not decrease monotonically when the beam quality is softened for the relevant range of clinical qualities. This is attributed to the significant back scattering from the superficial water layer toward the entrance surface for low-energy incident photons. This highlights the importance of including a superficial water layer, approximating the scalp of an adult patient, for the calculation of backscatter factors using "soft" beam qualities. 
Table 2. Ratios of backscatter factors calculated for differently dimensioned water phantoms. The backscatter factors correspond to an $18 \mathrm{~cm}$ diameter spherical phantom, $\left(B_{\text {air }}\right)_{\text {sphere,18 }}$, a $16 \mathrm{~cm}$ diameter spherical phantom, $\left(B_{\text {air }}\right)_{\mathrm{sphere}, 16}$, and a $18 \mathrm{~cm} \mathrm{x} 18 \mathrm{~cm} \mathrm{x} 18 \mathrm{~cm}$ cubic phantom, $\left(B_{\text {air }}\right)_{\text {cube,18 }}$. The backscatter factors are calculated for various cranial bone layer thicknesses and field sizes, for the three beam qualities (specified in terms of homogeneity coefficient, $h=$ $\mathrm{HVL}_{1} / \mathrm{HVL}_{2}$ ) detailed in table 1 .

\begin{tabular}{|c|c|c|c|c|c|c|c|}
\hline \multirow{2}{*}{ Beam Quality } & \multirow[b]{2}{*}{$\begin{array}{l}\text { Bone Thickness } \\
(\mathrm{mm})\end{array}$} & \multicolumn{3}{|c|}{$\left(B_{\text {air }}\right)_{\text {sphere,18 }} /\left(B_{\text {air }}\right)_{\text {sphere,16 }}$} & \multicolumn{3}{|c|}{$\left(B_{\text {air }}\right)_{\text {sphere }, 18} /\left(B_{\text {air }}\right)_{\text {cube,18 }}$} \\
\hline & & $5 \times 5 \mathrm{~cm}^{2}$ & $10 \times 10 \mathrm{~cm}^{2}$ & $15 \times 15 \mathrm{~cm}^{2}$ & $5 \times 5 \mathrm{~cm}^{2}$ & $10 \times 10 \mathrm{~cm}^{2}$ & $15 \times 15 \mathrm{~cm}^{2}$ \\
\hline \multirow[t]{6}{*}{$\mathrm{Q}_{1}(h=0.95)$} & 0 & 1.001 & 1.006 & 1.016 & 1.002 & 0.980 & 0.948 \\
\hline & 2.5 & 1.000 & 1.004 & 1.013 & 1.005 & 0.990 & 0.966 \\
\hline & 5.0 & 1.000 & 1.004 & 1.011 & 1.005 & 0.993 & 0.974 \\
\hline & 7.5 & 1.000 & 1.004 & 1.010 & 1.004 & 0.993 & 0.977 \\
\hline & 10.0 & 1.000 & 1.003 & 1.009 & 1.004 & 0.992 & 0.978 \\
\hline & 12.5 & 1.000 & 1.003 & 1.007 & 1.005 & 0.993 & 0.979 \\
\hline \multirow[t]{6}{*}{$\mathrm{Q}_{2}(h=0.84)$} & 0 & 1.000 & 1.005 & 1.014 & 1.004 & 0.984 & 0.958 \\
\hline & 2.5 & 1.001 & 1.004 & 1.011 & 1.006 & 0.997 & 0.979 \\
\hline & 5.0 & 1.000 & 1.003 & 1.008 & 1.005 & 0.998 & 0.985 \\
\hline & 7.5 & 1.000 & 1.002 & 1.006 & 1.005 & 0.998 & 0.988 \\
\hline & 10.0 & 1.000 & 1.002 & 1.006 & 1.005 & 0.997 & 0.990 \\
\hline & 12.5 & 1.000 & 1.003 & 1.005 & 1.005 & 0.998 & 0.991 \\
\hline \multirow[t]{6}{*}{$\mathrm{Q}_{3}(h=0.71)$} & 0 & 1.001 & 1.003 & 1.007 & 1.005 & 0.995 & 0.985 \\
\hline & 2.5 & 1.001 & 1.003 & 1.005 & 1.005 & 1.002 & 0.998 \\
\hline & 5.0 & 1.001 & 1.002 & 1.004 & 1.004 & 1.002 & 1.000 \\
\hline & 7.5 & 1.001 & 1.002 & 1.004 & 1.004 & 1.003 & 1.001 \\
\hline & 10.0 & 1.001 & 1.002 & 1.003 & 1.004 & 1.003 & 1.001 \\
\hline & 12.5 & 1.001 & 1.002 & 1.002 & 1.004 & 1.003 & 1.002 \\
\hline
\end{tabular}

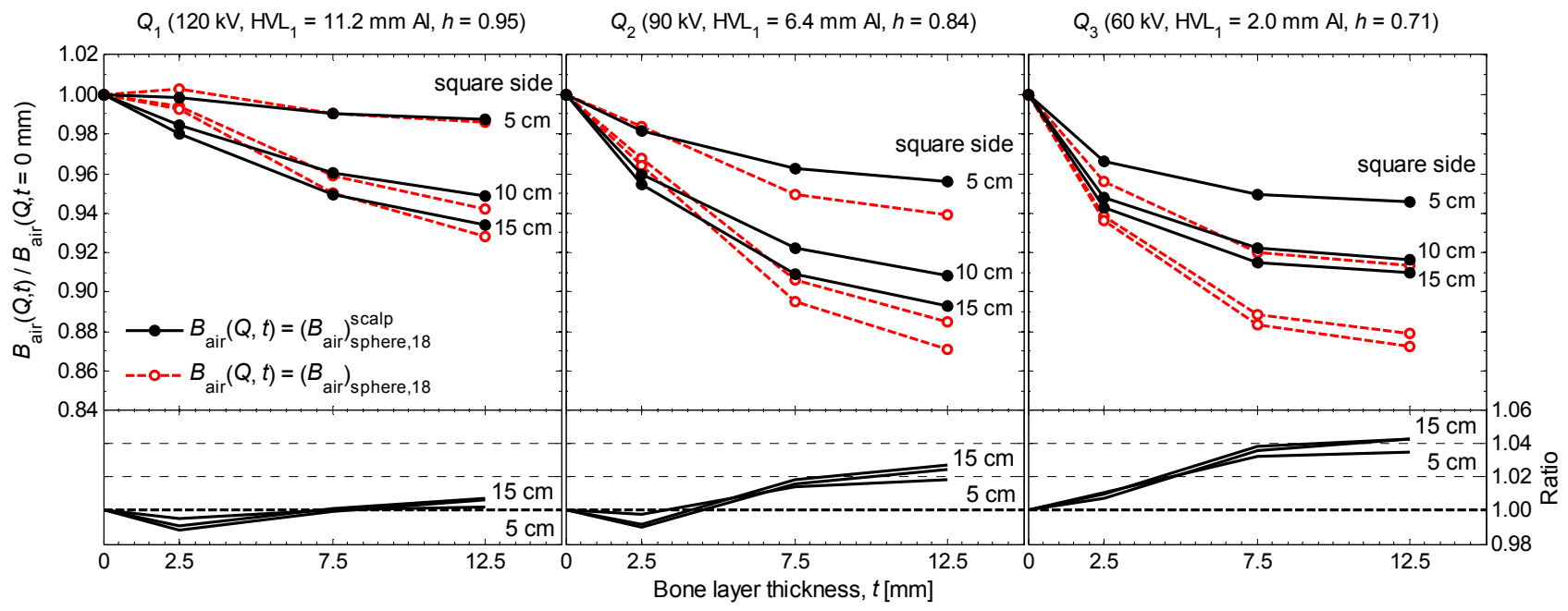

Figure 1. Backscatter factors calculated for different configurations of an $18 \mathrm{~cm}$ diameter spherical water phantom, as a function of the thickness of the cranial bone layer, for the beam qualities of Table 1 and three different field sizes. The results are normalized to a homogeneous water phantom (zero bone layer thickness). The factors correspond to a phantom

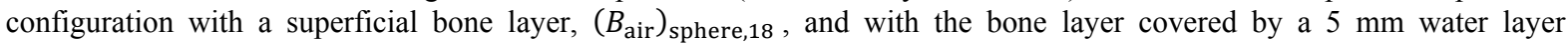
(approximating the adult scalp), $\left(B_{\text {air }}\right)_{\text {sphere,18 }}^{\text {scalp }}$. The lower panel of the figure shows ratios of backscatter factors with-towithout the scalp layer. 
The sensitivity of backscatter factors to the size, shape, and configuration of the head phantom model have been shown to be small, generally within $1-3 \%$. Therefore, although moderate differences in shape and size of an adult head compared to a stylized phantom are likely, backscatter factors calculated for a stylized head phantom are expected to be representative of the scatter from an adult patient head. Furthermore, the results validate the use of an $18 \mathrm{~cm}$ diameter spherical water phantom, containing a cranial bone layer at $5 \mathrm{~mm}$ depth, for Monte Carlo calculations of backscatter factors for neurointerventional radiology procedures. The proposed head phantom configuration will be used for the remainder of this work.

Figure 2 shows Monte Carlo calculated backscatter factors for monoenergetic photons, $B_{\text {air }}(E)$, at the surface of a water phantom containing a $6 \mathrm{~mm}$ thick cranial bone layer at a depth of $5 \mathrm{~mm}$. They are compared with the corresponding data from Benmakhlouf et al. ${ }^{8}$ calculated for a large homogeneous water phantom approximating the body of adult patients. Results are shown for two square field sizes. For both of them, the ratio of backscatter factors with-to-without a bone layer, shown in the lower panel, decreases with incident photon energy, reaching a minimum between $35 \mathrm{keV}-45 \mathrm{keV}$, after which the ratio increases. The non-monotonic behavior is due to the difference in the energy dependence of the photoelectric absorption and Compton scattering cross-sections in water and bone. Due to the higher effective atomic number of bone, its photoelectric cross-section is significantly larger than that of water. The bone layer therefore acts primarily as an absorber of low-energy photons, attenuating both primary incident and backscattered photons from the phantom, resulting in reduced backscatter factors. As the photon energy increases, Compton scattering becomes the dominant process, and due to the higher electron density of cranial bone than of water, the bone layer increases the scatter of photons compared to water, resulting in slightly increased backscatter factors. This can be noticed in Figure 2 for the $5 \mathrm{~cm}$ x $5 \mathrm{~cm}$ field size for incident photon energies above $120 \mathrm{keV}$, where the backscatter factors calculated with a bone layer are slightly larger than those calculated without the bone layer.

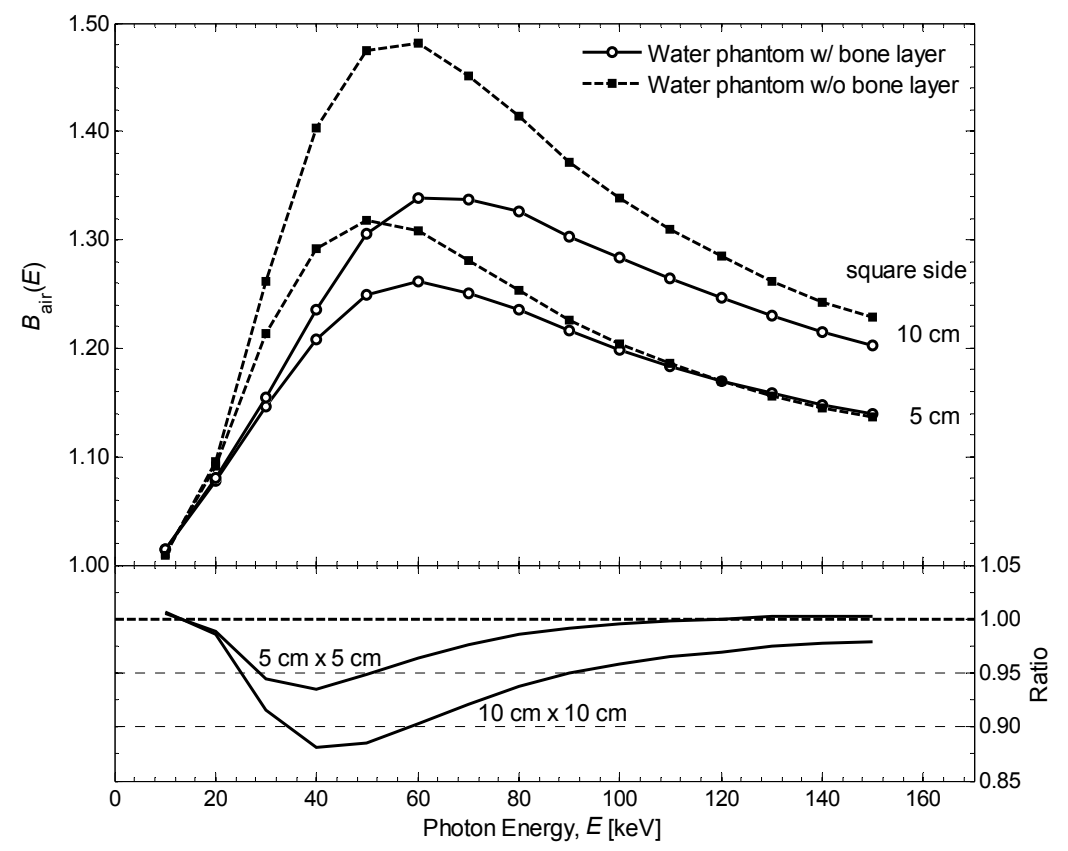

Figure 2. Monte Carlo calculated backscatter factors at the entrance surface of a water phantom containing a cranial bone layer, for monoenergetic photons and two square field sizes (solid lines). The data corresponds to simulations using an $18 \mathrm{~cm}$ diameter spherical water phantom with a $6 \mathrm{~mm}$ thick cranial bone layer (w/ bone layer) at $5 \mathrm{~mm}$ depth. Results from Benmakhlouf et al. ${ }^{8}$ for a $15 \mathrm{~cm}$ thick homogeneous water phantom (w/o bone layer) approximating the body of adult patients are included for comparison. The lower panel of the figure shows ratios of backscatter factors with-to-without the cranial bone layer. 


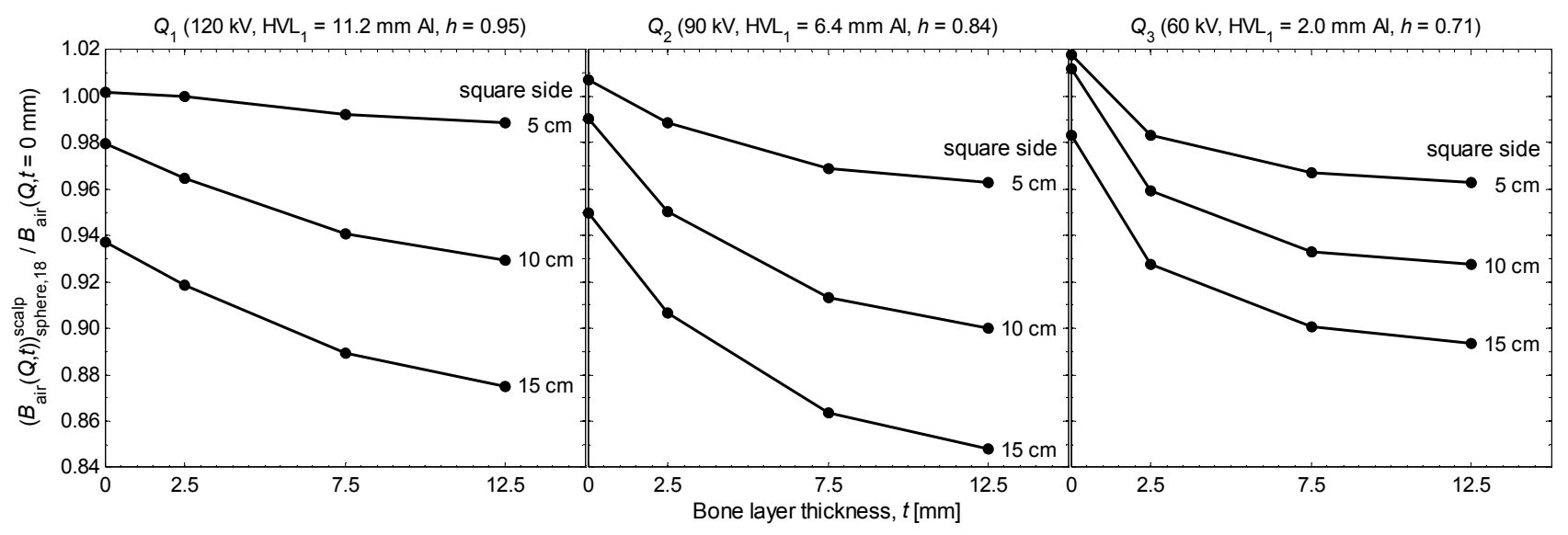

Figure 3. Monte Carlo calculated backscatter factors at the entrance surface of an $18 \mathrm{~cm}$ diameter spherical water phantom

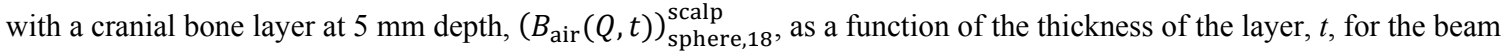
qualities of Table 1 and three different field sizes. The results are normalized to backscatter factors calculated for a homogeneous water phantom approximating the body of adult patients, $B_{\mathrm{air}}(Q, t=0)$, i.e., to conventional backscatter factors for a cubic $30 \mathrm{~cm}$ x $30 \mathrm{~cm}$ front surface and $15 \mathrm{~cm}$ thick phantom.

Figure 3 shows Monte Carlo calculated backscatter factors for an $18 \mathrm{~cm}$ diameter spherical water phantom with a cranial bone layer at $5 \mathrm{~mm}$ depth, as a function of the cranial bone layer thickness for different field sizes and beam qualities. The results are normalized to backscatter factors calculated for a homogeneous water phantom dimensioned to approximate the body of adult patients, i.e., to conventional backscatter factors. The results show a decrease of the backscatter factors for the softer incident beam qualities when the field size increases. For the field size dependence, the amount of large angle scattered and multiple scattered low-energy photons increases with field size, resulting in an increased amount of low-energy photons absorbed in the bone layer. For thicker bone layers the reduction is more accentuated due to the increased attenuation of both primary and backscattered photons. For beam quality $\mathrm{Q}_{3}$ the decrease in backscatter factors for the larger field sizes and thicker bone layers is, compared with the harder beam qualities, smaller than expected. This is due to the significant scattering of primary incident photons from the superficial water layer to the phantom entrance surface, which is greater for "soft" incident beam qualities and large field sizes. Overall, the results show that for the clinical beam qualities studied the bone layer acts primarily as an absorber of lowenergy photons, reaching a reduction of up to $15 \%$ in backscatter factors calculated with a cranial bone layer compared to conventional backscatter factors.

\section{CONCLUSIONS}

Backscatter factors calculated at the entrance surface of a water phantom containing a cranial bone layer, and dimensioned to approximate the head of an adult patient during interventional neuroradiology procedures, have been investigated. They have been found to be substantially smaller, by up to $15 \%$, than those conventionally used in the dosimetry of radiodiagnostic beams, which are based on a large homogeneous water phantom. This has been shown to be due to the cranial bone layer acting primarily as an absorber of low-energy photons, attenuating both primary incident and phantom backscattered photons. Including the effect of the scalp thickness (simulated as a $5 \mathrm{~mm}$ thick water layer) has been found to increase the differences by up to $4 \%$. Also, the difference in backscatter factors calculated in this work compared with those conventionally used is shown to be significantly dependent on beam quality and field size, the difference ranging from about $1-14 \%$ for a bone layer thickness of $7.5 \mathrm{~mm}$. The use of current recommended values would overestimate patients' skin doses. The results point at the need to establish a set of suitable backscatter factors, calculated using the methodology presented here, to achieve a more accurate determination of the skin dose in patients that undergo neurointerventional radiology procedures. 


\section{REFERENCES}

[1] UNSCEAR 2008 Report: Volume I: Sources - Report to the General Assembly Scientific Annexes A and B, "Sources and Effects of Ionizing Radiation" (2008)

[2] ICRP Publication 118, "ICRP statement on tissue reactions and early and late effects of radiation in normal tissues and organs - threshold doses for tissue reactions in a radiation protection context," Ann. ICRP 41, 1-2 (2012)

[3] ICRP Publication 85, "Avoidance of radiation injuries from medical interventional procedures," Ann. ICRP 30, 7-67 (2000)

[4] Miller, D., Balter, S., Schueler, B., Wagner, L., Strauss, K. and Vano, E., "Radiation management for fluoroscopically guided procedures" Radiology 257(2), 321-332 (2010)

[5] ICRU Report 74, "Patient Dosimetry for X Rays Used in Medical Imaging," Bethesda, MD: International Commission on Radiation Units and Measurements (2006)

[6] IAEA Technical Reports Series no. 457, "Dosimetry in Diagnostic Radiology: An International Code of Practice," International Atomic Energy Agency Vienna: IAEA (2007)

[7] Petoussi-Henss, N., Zankl, M., Drexler, G., Panzer, W. and Regulla, D., "Calculation of backscatter factors for diagnostic radiology using Monte Carlo methods," Phys. Med. Biol. 43, 2237-50 (1998)

[8] Benmakhlouf, H., Bouchard, H., Fransson, A. and Andreo, P., "Backscatter factors and mass energyabsorption coefficient ratios for diagnostic radiology dosimetry," Phys. Med. Biol., 56 7179-7204 (2011)

[9] Benmakhlouf, H., Fransson, A. and Andreo, P., "Influence of phantom thickness and material on the backscatter factors for diagnostic x-ray beam dosimetry," Phys. Med. Biol. 58, 247-260 (2003)

[10] Ma, C-M. and Seuntjens, J. P., "Mass-energy absorption coefficient and backscatter factor ratios for kilovoltage x-ray beams," Phys. Med. Biol. 44, 131-143 (1999)

[11] Butson, M., Tsang, C. and Peter, Y., "Measurement of dose reductions for superficial x-rays backscattered from bone interfaces," Phys. Med. Biol. 53, N329-N336 (2008)

[12] Sempau, J. and Badal, A., "PenEasy, a modular main program and voxelised geometry package for PENELOPE," (2010) http://www.upc.edu/inte/downloads/penEasy.htm

[13] Salvat, F., Fernández-Varea, J. M. and Sempau, J., "PENELOPE, a code system for Monte Carlo simulation of electron and photon transport," Issy-les-Moulineaux: OECD Nuclear Energy Agency (2010)

[14] Hubbell, J. H. and Seltzer, S. M., "Tables of x-ray mass attenuation coefficients and mass energy absorption coefficients," Gaithersburgh, MD: National Institute of Standards and Technology, (version 1.4; 2004) http://physics.nist.gov/xaamdi

[15] ICRU Report 46, "Photon, electron, proton, and neutron interaction data for body tissues," Bethesda, MD: International Commission on Radiation Units and Measurements (1992)

[16] Lynnerup, N., "Cranial thickness in relation to age, sex and general body build in a Danish forensic sample," Forensic Sci. Int. 117, 45-51 (2001)

[17] Moreira-Gonzalez, A., Papay, F. E. and Zins, J. E., "Calvarial thickness and its relation to cranial bone harvest," Plast. Reconstr. Surg. 117(6), 1964-1971 (2006)

[18] Hori, H., Moretti, G., Rebora, A. and Crovato, F., "The thickness of human scalp: normal and bald," J. Invest. Derm. 58, 396-399 (1972)

[19] AAPM Report No. 54, "Stereotactic Radiosurgery," American Association of Physicists in Medicine, College Park (1995)

[20] Huda, W., Lieberman, A. K., Chang, J. and Roskopf, L. M., "Patient size and x-ray technique factors in head computed tomography examinations. I. Radiation doses," Med. Phys. 31(3), 588-59 (2004)

[21] Poludniowski, G., Landry, G., DeBlois, F., Evans, P. M. and Verhaegen, F., "SpekCalc: a program to calculate photon spectra from tungsten anode x-ray tubes," Phys. Med. Biol. 54, N433-N438 (2009) 